\title{
Chapter 15 \\ Effect of Nitrogen Fertilization on Radiocesium Absorption in Soybean
}

\author{
Naoto Nihei, Atsushi Hirose, Mihoko Mori, Keitaro Tanoi, \\ and Tomoko M. Nakanishi
}

\begin{abstract}
Radioactive materials that were released during the nuclear accident contaminated the soil and agricultural products. It has become clear that potassium fertilization is effective for the reducing radiocesium concentrations in agricultural crops. However, apart from reports about potassium, few reports have examined how nitrogen $(\mathrm{N})$, which has a large effect on crop growth, contributes to the radiocesium absorption. Focusing on this point, we studied the effect of nitrogen fertilizer on the radiocesium absorption in soybean seedlings. The concentration of radiocesium in the seed of soybean was higher in nitrogen-fertilized plants than in plants grown without fertilizer. The radiocesium concentration in the aboveground biomass increased as the amount of nitrogen fertilization increased. A comparison of the effects of the different forms of nitrogen treatment shows that the highest radiocesium concentration in the aboveground biomass occurred with ammonium sulfate (approximately 3.7 times the non-N), the next highest absorption occurred with ammonium nitrate (approximately 2.4 times the non-N treatment), followed by calcium nitrate (approximately 2.2 times the non- $\mathrm{N}$ treatment). Furthermore, the amount of radiocesium in soil extracts was highest with ammonium-nitrogen fertilization. Further study is required to clarify the factors that incur an increase in radiocesium concentration in response to nitrogen fertilization. Special care is required to start farming soybean on fallow fields evacuated after the accident or on fields where rice has been grown before, which tend to have higher available nitrogen than the regularly cultivated fields.
\end{abstract}

Keywords Radiocesium $\bullet$ Soybean $\bullet$ Nitrogen $\bullet$ Ammonium

N. Nihei $(\bowtie) \bullet$ A. Hirose $\bullet$ M. Mori $\bullet$ K. Tanoi $\bullet$ T.M. Nakanishi

Graduate School of Agricultural and Life Science, The University of Tokyo, 1-1-1, Yayoi,

Bunkyo-ku, Tokyo, Japan

e-mail: anaoto@mail.ecc.u-tokyo.ac.jp 


\subsection{Introduction}

The Great East Japan Earthquake occurred on March 11, 2011, and it was immediately followed by the accident at the Fukushima Daiichi Nuclear Power Plant, Tokyo Electric Power Company. Radiocesium, the dominant nuclide released during the accident, reached agricultural lands in Fukushima and its neighboring prefectures and contaminated the soil and agricultural products $[1,2]$. To guarantee the safe consumption and handling of agricultural, livestock, forestry, and marine products, monitoring inspections were established [3]. According to these inspections [4-6] the ratio of samples exceeding the new standard value of radiocesium [7] (100 Bq $\mathrm{kg}^{-1}$ ) were found to be $5.7 \%$ for soybean, $2.6 \%$ for rice, and $11 \%$ for wheat in $2011 ; 2.6 \%$ for soybean, $0.0007 \%$ for rice, and $0 \%$ for wheat in 2012 ; and $1.9 \%$ for soybean, $0.0003 \%$ for rice, and $0 \%$ for wheat in 2013. The inspection results indicate that the ratio of soybean exceeding $100 \mathrm{~Bq} \mathrm{~kg}^{-1}$ was high compared with that for rice and wheat and that the tendency to decline was low compared with that for rice and wheat. To revitalize agriculture, Fukushima Prefecture has been promoting the decontamination of agricultural lands; consequently, it has implemented an increase in the exchangeable potassium content in soil used to grow

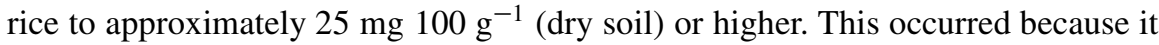
recently became clear that potassium fertilization was effective for reducing the radiocesium concentration in agricultural crops $[8,9]$. Nitrogen $(\mathrm{N})$ has a large effect on crop growth, and some reports have suggested that it also promotes the radiocesium absorption $[10,11]$. However, few studies have examined how nitrogen contributes to the radiocesium absorption in soybean apart from potassium.

For the recovery and revitalization of agricultural industries, the analysis of radiocesium absorption in soybeans is necessary. Focusing on this point, we studied the effect of nitrogen fertilizers on the radiocesium absorption in soybean seedlings.

\subsection{Materials and Methods}

We cultured soybean (Glycine max) in a greenhouse (experiment 1) and in a field (experiment 2). For experiment 1, nitrogen fertilizer in the form of ammonium sulfate was applied at two levels: 0.4 and $1.3 \mathrm{~g}$ per $1 \mathrm{~L}$ pot (hereafter low-N and high$\mathrm{N}$, respectively). The radiocesium activity of the soil which was taken in Fukushima in August 2012 was approximately $30 \mathrm{kBq} \mathrm{kg}^{-1}$, exchangeable potassium was $13.4 \mathrm{mg} 100 \mathrm{~g}^{-1}$ soil, and $\mathrm{pH}$ was 6.0. The plants were grown until maturity, and the seed was collected. For experiment 2, soybean was grown in Iitate Village, Fukushima Prefecture. The radiocesium of the field was approximately $13 \mathrm{kBq}$ $\mathrm{kg}^{-1}$ (15-cm depth), exchangeable potassium was $15.8 \mathrm{mg} 100 \mathrm{~g}^{-1}$, and $\mathrm{pH}$ was 6.2. Nitrogen fertilizer in the form of ammonium nitrate was applied at three levels: 0,50 , and $100 \mathrm{~kg} \mathrm{ha}^{-1}$ (hereafter non-N, low-N, and high-N, respectively). We sowed the seeds for experiment 2 on June 16, 2014, and collected the aboveground 
biomass on September 2, 2014. Next, we studied the effect of the different forms of nitrogen treatment on radiocesium absorption by soybean seedling (experiment 3 ). Nitrogen was applied as calcium nitrate, ammonium nitrate, and ammonium sulfate at three levels: $0,0.01$, and $0.05 \mathrm{~g}$ per treatment (hereafter non-N, low-N, and high$\mathrm{N}$, respectively). We cultured soybean in a vessel $(6.5 \times 6.5 \times 6.5 \mathrm{~cm})$ for 18 days in a biotron $\left(28{ }^{\circ} \mathrm{C}, 16 \mathrm{~h} \mathrm{light}\right)$. We collected the aboveground biomass. Moreover, we studied radiocesium activity in soil extracts following nitrogen application (experiment 4). Nitrogen was applied to the soil at $0.5 \mathrm{~g} \mathrm{~kg}^{-1}$ as ammonium sulfate. We collected the soil after 1,5 , and 15 days, extracted it with $1 \mathrm{M}$ calcium chloride, and then measured the radiocesium activity. We used soil sourced from the same batch in Experiment 1, 3, and 4. The radiocesium activities of all samples were measured using a sodium iodide scintillation counter (Aloka AM-300). In experiment 3 , potassium, calcium, and magnesium concentrations in the soybean seedling were measured after acid decomposition using inductively coupled plasma optical emission spectrometry (ICP-OES) (PerkinElmer, Optima 7300).

\subsection{Results}

Figure 15.1 shows the effect of nitrogen fertilizer on radiocesium absorption by soybean. The concentrations of radiocesium in the seed (experiment 1) or the aboveground biomass (experiment 2) were higher in the high-N treatments than in the non-N or low-N treatments. Table 15.1 shows the influence of the different forms of nitrogen treatment on radiocesium activity in the aboveground (experiment 3 ). The highest activity occurred with ammonium sulfate (approximately 3.7 times the non- $\mathrm{N}$ treatment), the next highest activity occurred with ammonium nitrate (approximately 2.4 times the non-N treatment), followed by calcium nitrate (approximately 2.2 times the non- $\mathrm{N}$ treatment). The concentrations of radiocesium in the
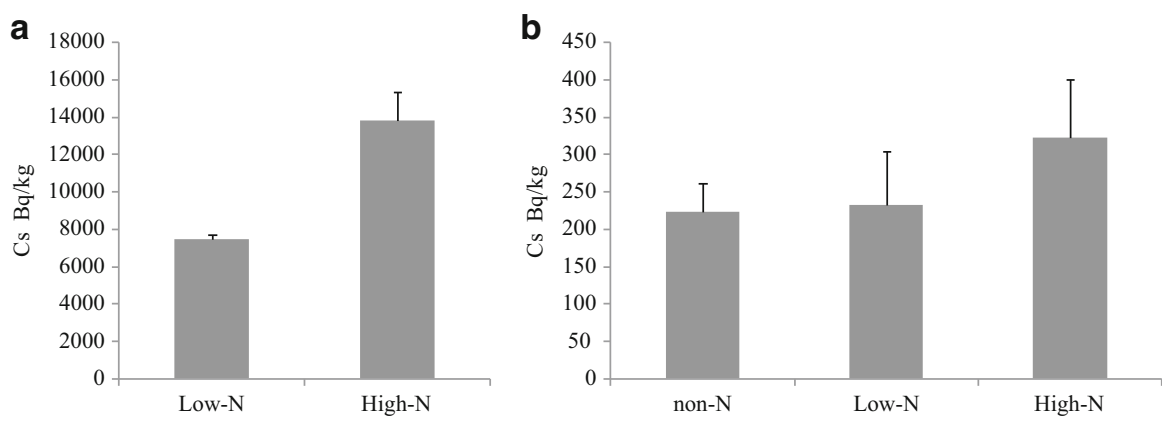

Fig. 15.1 (a) Experiment 1. The plants were cultured until maturity within $1 \mathrm{~L}$ pot, and the seed was analyzed. (b) Experiment 2. The plants were cultureed in Iitate village, Fukushima prefecture, and the aboveground biomass was analyzed 
Table 15.1 Radiocesium activities and concentrations of base cations in soybean aboveground biomass after nitrogen fertilization treatments (Experiment 3)

\begin{tabular}{l|l|l|l|l|l|l|l|l}
\hline \multirow{2}{*}{ Treatment } & $\mathrm{Cs}$ & $\mathrm{K}$ & $\mathrm{Ca}$ & $\mathrm{Na}$ & $\mathrm{P}$ & Dry weight & Height \\
\cline { 3 - 10 } & & $\mathrm{Bq} \mathrm{kg}^{-1}$ & $\mathrm{mg} \mathrm{g}^{-1}$ & $\mathrm{mg} \mathrm{g}^{-1}$ & $\mathrm{mg} \mathrm{g}^{-1}$ & $\mathrm{mg} \mathrm{g}^{-1}$ & $\mathrm{~g} \mathrm{plant}^{-1}$ & $\mathrm{~cm}$ \\
\hline \multirow{2}{*}{ (Control) } & Non-N & 440 & 21 & 3.3 & 0.09 & 2.0 & 1.6 & 28 \\
\hline \multirow{2}{*}{ Ammium nitrate } & Low-N & 464 & 22 & $4.8^{* *}$ & 0.09 & 2.0 & 1.6 & 30 \\
\cline { 2 - 9 } & Hihg-N & 984 & 24 & $8.1^{* *}$ & $0.22^{*}$ & 1.5 & 1.3 & $17^{*}$ \\
\hline \multirow{2}{*}{ Ammonium nitrate } & Low-N & 642 & 22 & 3.6 & 0.12 & 2.6 & 1.4 & 25 \\
\cline { 2 - 9 } & Hihg-N & $1077^{* *}$ & 19 & 3.4 & 0.09 & 2.3 & 1.6 & 29 \\
\hline
\end{tabular}

$* p<0.05, * * p<0.01$ compared to the control (Dunnet's test)

Fig. 15.2 Radiocesium extracted from the soil after nitrogen fertilization (Experiment 4)

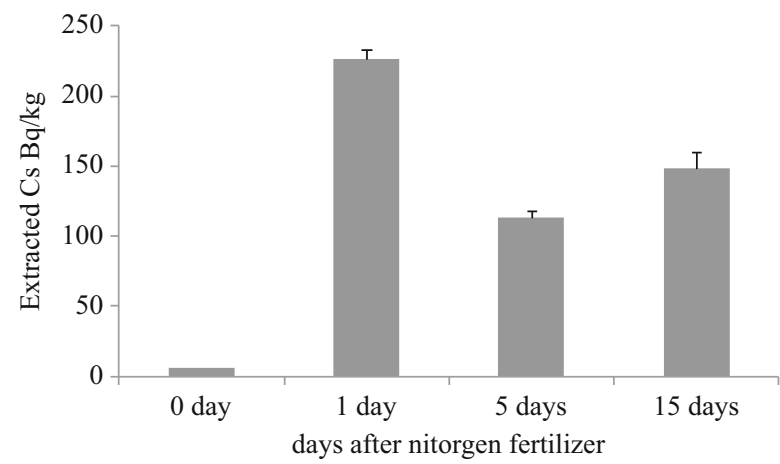

aboveground biomass were higher in nitrogen-fertilized plants than in plants without added nitrogen. Figure 15.2 shows the radiocesium activity in soil with applied nitrogen (experiment 4). The amount of extracted radiocesium increased a day after fertilization and remained higher even after 15 days of nitrogen application.

\subsection{Discussion}

The radiocesium concentration in seed and aboveground biomass increased as the amount of nitrogen fertilizer increased. The different forms of nitrogen treatment increased the radiocesium concentration of soybean in the order ammonium sulfate $>$ ammonium nitrate $>$ calcium nitrate. Hence, ammonium-nitorogen increased radiocesium absorption more than nitrate. Furthermore, the amount of radiocesium extracted from the soil, which is considered potentially available for plant absorption, was increased by ammonium-nitrogen fertilization.

Geometrically adapted cesium ions are fixed to the clay mineral, and the radiocesium adsorbed to the soil particles was probably not available for plant uptake. But the ionic radius of the ammonium ion is similar to that for the cesium 
ion [10], ammonium exchanged, and released radiocesium from the soil. We found that the amount of radiocesium extracted by ammonium fertilizer increased the day after fertilization; therefore, soybean could absorb radiocesium. In addition, the ammonium and cesium ions are both univalent cations, and ammonium has been found to restrict cesium absorption in the hydroponics [9-11]. This study was used by soil. It was considered that ammonium oxidizes to nitrate during cultivation, and ammonium fertilization did not restrict the radiocesium absorption of soybean. Moreover, we considered that potassium absorption might compete with ammonium absorption because both ions are univalent cations; hence, the soybeans may lack potassium. A lack of potassium has been found to increase cesium absorption $[9,12,13]$. However, the potassium concentrations in soybean did not decrease with ammonium fertilization. Therefore, we suggest that the increased activity of radiocesium in soybean due to ammonium fertilization was not because of a lack of potassium.

Soybean cultivation typically follows rice cultivation. To assist the recovery and revitalization of agricultural industries in Fukushima Prefecture, we suggest that special care is required to select the appropriate kind of fertilizer and to start cultivating soybean on fields that have higher available nitrogen than the regular cultivated fields. It is important to clarify the mechanism of cesium availability in response to nitrogen fertilizers to cope with cesium contamination in crops.

Open Access This chapter is distributed under the terms of the Creative Commons Attribution Noncommercial License, which permits any noncommercial use, distribution, and reproduction in any medium, provided the original author(s) and source are credited.

\section{References}

1. Yasunari TJ, Stohl A, Hayano RS, Burkhart JF, Eckhardt S, Yasunari T (2011) Cesium-137 deposition and contamination of Japanese soils due to the Fukushima nuclear accident. Proc Natl Acad Sci U S A 108:19530

2. Zheng J, Tagami K, Bu W, Uchida S, Watanabe Y, Kubota Y, Fuma S, Ihara S (2014) ${ }^{135} \mathrm{Cs} /{ }^{137} \mathrm{Cs}$ isotopic ratio as a new tracer of radiocesium released from the Fukushima nuclear accident. Environ Sci Technol 48:5433

3. Nihei N (2013) Radioactivity in agricultural products in Fukushima. In: Nakanishi TM, Tanoi $\mathrm{K}$ (eds) Agricultural implications of the Fukushima nuclear accident. Springer, Tokyo/New York, pp 73-85

4. Hamada N, Ogino H, Fujimichi Y (2012) Safety regulations of food and water implemented in the first year following the Fukushima nuclear accident. Radiat Res 53:641

5. Fukushima Prefecture (2011) (Toward a new future of Fukushima): http://www.newfukushima.jp/monitoring/en/ Accessed 10 May 2015

6. Nihei N (2015) Monitoring inspection in Fukushima prefecture and radiocesium absorption of soybean (in Japanese). Isot News 73:118-123

7. Nihei N, Tanoi K, Nakanishi TM (2015) Inspections of radiocesium concentration levels in rice from Fukushima Prefecture after the Fukushima Dai-ichi Nuclear Power Plant accident. Scientific reports 5, Article number: 8653-8658(2015/3) 
8. Zhu YG, Shaw G, Nisbet AF, Wilkins BT (2000) Effects of external potassium supply on compartmentation and flux characteristics of radiocaesium in intact spring wheat roots. Ann Bot 85:293-298

9. Sanchez AL, Wright SM, Smolders E, Nayor C, Stevens PA, Kennedy VH, Dodd BA, Singleton DL, Barnett CL (1999) High plant uptake of radiocesium from organic soils due to Cs mobility and low soil K content. Environ Sci Technol 33:2752-2757

10. Tensyo K, Yeh KL, Mitsui S (1961) The uptake of strontium and cesium by plants from soil with special reference to the unusual cesium uptake by lowland rice and its mechanism. Soil Plant Food 6:176

11. Ohmori $Y$ et al (2014) Difference in cesium accumulation among rice cultivars grown in the paddy field in Fukushima Prefecture in 2011 and 2012. J Plant Res 127:57-63

12. Cline JF, Hungate FP (1960) Accumulation of potassium, cesium137, and rubidium 86 in bean plants grown in nutrient solutions. Plant Physiol 35:826. doi:10.1104/pp.35.6.826

13. Evans EJ, Dekker AJ (1969) Effect of nitrogen on cesium 137 in soils and its uptake by oat plants. Can J Soil Sci 49:349-355 